\title{
Partial minimum wage compliance
}

\author{
Haroon Bhorat ${ }^{1 *}$, Ravi Kanbur ${ }^{2}$ and Benjamin Stanwix ${ }^{1}$
}

\author{
* Correspondence: \\ haroon.bhorat@uct.ac.za \\ ${ }^{1}$ Development Policy Research Unit, \\ University of Cape Town, Cape \\ Town 7700, South Africa \\ Full list of author information is \\ available at the end of the article
}

\begin{abstract}
In many developing countries, a significant portion of the wage distribution is found below the legal minimum wage. In order to fully understand the nature of this non-compliance, we need to compare the counterfactual wage distribution without the minimum wage law to the current wage distribution. Such a comparison could reveal partial compliance, where employers raise wages some of the way to the minimum wage, to balance out the benefits of non-compliance with the costs and penalties to the extent that they depend on the gap between the legal minimum wage and the wage actually paid. This paper presents a simple model of such partial compliance and uses its predictions to structure an empirical investigation of the impact of introducing a minimum wage law for agricultural workers in South Africa. We find that partial compliance is indeed taking place and further, the lowest wages are being raised disproportionately, consistent with the predictions of the model. JEL codes: J23, J25, J31, J32, J38, J43

Keywords: Minimum Wages, South Africa, Compliance, Enforcement, Agriculture, Index of Minimum Wage Violation, Wage
\end{abstract}

\section{Introduction}

According to basic theory, the introduction of a fully enforced minimum wage in a perfectly competitive labor market will increase the wages of the employed to the minimum wage, but reduce employment. As minimum wages have been introduced and increased in many countries around the world, there have been extensive empirical assessments of the economic and welfare consequences of such an intervention. Whilst the evidence remains predominantly concentrated in developed economies, empirical assessments for the developing world are growing in prevalence. The effects on employment remain intensely debated in large part due to the substantive heterogeneity in measured outcomes. Indeed, the impact of a minimum wage on employment remains the dominant question in the literature.

But in many countries, then particularly in developing countries, a significant portion of the wage distribution is found below the legal minimum wage. Less focus and attention has been given to understanding changes in wage levels below the stipulated legal minimum, given that the legislation is rarely fully enforced. In order to understand the nature of this non-compliance, we need to compare the counterfactual wage distribution without the minimum wage law to the current wage distribution. Such a comparison could reveal partial compliance with the law. There are two senses in which a firm's compliance with a minimum wage regulation could be partial, relative to the situation with no regulation. First, the firm could raise the wage it pays its workers somewhat but not all the way to the minimum wage. Second, it could pay some of its 
workers the minimum wage, and others the subminimum wage. The choice between these strategies will depend on the enforcement regime-the probability of being caught, and the level and structure of penalties if caught. It will also depend on nonofficial, social costs of non-compliance.

Our previous work on minimum wage regulation in South Africa has quantified the degree of non-compliance, taking into account not only the fact of violation but also the extent and depth of violation of the minimum wage law (Bhorat et al. 2012, 2013a). We have introduced an index of minimum wage violation which assigns different weights to the depth of violation, and tried to relate this to enforcement resources (Bhorat et al. 2013b). Other work has also explored the employment consequences of the introduction of the minimum wage law in different sectors, including in agriculture where, for example, we have found evidence of both employment losses and rising wages (Bhorat et al. 2014). There is limited work internationally in trying to understand responses to the minimum wage below the minimum wage. The work of Neumark et al. (2000) though, does attempt to model how minimum wages changes impact on the wages of workers throughout the wage distribution. As such then, it is a key insight of the paper that employment, wage and hours of work responses, of low-wage versus high-wage workers to minimum wage changes, will differ. There is however, no framework here building below minimum wage levels as a measure of non-compliance.

Our objective in this paper is to provide a model and empirical evidence of partial compliance as a response to the promulgation of a minimum wage. The model predicts partial adjustment of wages and furthermore predicts, under certain conditions, that the lowest wages will be adjusted upwards disproportionately. Using fourteen waves of the South African Labour Force Survey (LFS) which span the introduction of the minimum wage, we test for these predictions using an index of non-compliance or violation, and find that the predictions of the model are borne out in the data.

The plan of the paper is as follows. Section 2 sets out the theoretical model to aid intuition and to structure our empirical work. It shows how even in a competitive labor market, imperfect enforcement can lead to a distribution of wages between the minimum wage and the competitive wage. Section 3 introduces our dataset, briefly describes the institutional structure of minimum wage enforcement in South African agriculture, and sets out the empirical strategy. With this background, in Section 4 we present the empirical results on partial wage compliance in South African agriculture. Section 5 concludes the paper.

\section{A simple model of partial compliance}

The basic reference in the literature on minimum wage compliance is Ashenfelter and Smith (1979). This paper formulated the gains from non-compliance taking into account the probability of getting caught and the penalty if caught, and applied the theory to the US minimum wage. Their measure of non-compliance was based on whether a worker was earning below the sectoral minimum wage, and not on the depth of the violation. They argued that "government enforcement, while not inducing anything like complete compliance, does have an impact" (p 333). Ashenfelter and Smith (1979) theoretical argument was modified, corrected and extended in a series of papers (Grenier, 1982; Chang and Ehrlich, 1985; Yaniv, 2001). Chang and Ehrlich (1985) 
for example, pointed out that neither Ashenfelter and Smith (1979) nor Grenier (1982), fully incorporated the firm's employment responses to the enforcement regime itself. They also introduced a formulation of the penalty of being caught as a multiple of the total underpayment of wages relative to the minimum wage.

Ashenfelter and Smith (1979), Grenier (1982), and Chang and Ehrlich (1985) all assumed the firm to be risk neutral. Yaniv (2001) extended the earlier analysis by introducing risk aversion, and also by introducing partial non-compliance, which he modelled as the firm deciding to pay some workers the minimum wage and others the competitive wage. Yaniv (2001) retains the Chang and Ehrlich (1985) formulation of the penalty, but introduced the dependence of the probability of inspection (and therefore the probability of getting caught) on the number of workers not receiving the minimum wage, and the penalty as increasing in the number of workers not being paid the minimum wage. The most striking result of Yaniv (2001) is that the total employment is independent of the enforcement parameters, depending only on the minimum wage as if it was fully enforced. Where enforcement makes an impact is on how many workers are paid the minimum wage. However, note Yaniv's (2001) assumption that all workers not paid the minimum wage are paid the competitive wage, whereas firms could in fact pay these workers somewhat higher wages so as to reduce the penalty if caught. We emphasize this dimension of adjustment in this paper.

All of the above analyses are in the context of a competitive labor market. Basu et al. (2010) take up the strand of the literature which follows on from Stigler's (1946) analysis for a monopsonistic labor market. For this case they analyze the determinants of the minimum wage and enforcement intensity chosen by the government, to optimize an objective function taking into account both equity and efficiency. On the way to this they show that the non-complying monopsonist will choose a wage level between the low monopsony wage and the higher, but imperfectly enforced, minimum wage. In this sense there is also partial compliance which again depends on the enforcement variables.

We will focus here on the competitive labor market case and present a simple model of partial compliance which combines elements from different parts of the literature, to motivate and to frame the empirical analysis to follow. The linear-quadratic formulation employed here is simple enough to give closed form solutions, but rich enough to ground intuitions and suggest empirical approaches.

Let output $y$ be given by

$$
y=a l-\left(\frac{1}{2}\right) b l^{2}
$$

where $l$ is labor and $a$ and $b$ are parameters of the production function which differentiate firms from each other.

If the wage is $w$ then profit is

$$
\pi=a l-\left(\frac{1}{2}\right) b l^{2}-w l
$$

For a competitive firm facing a wage $w^{c}$ the profit maximizing level of employment and associated profit are given respectively by:

$$
l^{c}=\left(a-w^{c}\right) / b
$$




$$
\pi^{c}=\left(a-w^{c}\right)^{2} / 2 b
$$

Now introduce a minimum wage $m$. With full enforcement the employment level and profits are of course given by:

$$
\begin{aligned}
& l^{m}=(a-m) / b \\
& \pi^{m}=(a-m)^{2} / 2 b
\end{aligned}
$$

These will be useful as reference points for later comparison.

Clearly, with $m>w^{c}$, employment and profits are lower with a fully enforced minimum wage. Thus there are incentives for non-compliance; the extent of which will depend on the probability of getting caught and the fine if so caught. As noted in the introduction, there are two dimensions of non-compliance: The subminimum wage that is paid, and the number of workers who are paid this low wage. In this model we focus on the first of these dimensions, and all workers will be paid the subminimum wage in the event of non-compliance. ${ }^{1}$ The firm is assumed to be risk neutral. Denoting the probability of inspection as $p$ and the fine as $f$, the expected profit when the wage paid is $w$ is given by:

$$
\pi^{e}=a l-\left(\frac{1}{2}\right) b l^{2}-w l-p f
$$

What determines $p$ and $f$ ? The institutional framework in many countries, including South Africa as described in the next section, is that inspections are determined by a combination of complaints received and targeted inspections by the inspectorate. We assume that the probability of receiving a complaint is proportional to the underpayment $(m-w)$. Further, given the cost effectiveness of inspecting larger establishments, we assume that the probability of targeted inspections increases with size of establishment. Putting these considerations together, we specify $p$ as:

$$
p=\lambda(m-w) l
$$

where $\lambda$ is a constant of proportionality $(>0)$. On the fine if caught, we follow most minimum wage enforcement regimes in making it a multiple of the total underpayment:

$$
f=\gamma(m-w) l
$$

where $\gamma>0$.

Putting together the expressions for $p$ and $f$ we get expected profits as:

$$
\pi^{e}=a l-\left(\frac{1}{2}\right) b l^{2}-w l-\left(\frac{1}{2}\right) \lambda \gamma(m-w)^{2} l^{2}
$$

where the multiple $\left(\frac{1}{2}\right)$ has been introduced in the last term to simplify the expressions that follow without affecting anything of substance. We now model this risk neutral firm as maximizing profits by choosing two variables. First is the usual choice of employment $l$. The second, however, is the choice of wage $w$ to pay. Since the minimum wage $m$ has been set to be above the competitive wage $w^{c}$, so 
long as $w$ is also chosen to be above the competitive wage, the firm can get all the workers it wants at wage $w$. Of course, the choice of $l$ and $w$ has to take into account the fact that these choices will affect the probability of inspection and the fine if caught.

Maximizing $\pi^{e}$ with respect to $l$ and $w$, the first order conditions are given by:

$$
\begin{aligned}
& \frac{\partial \pi^{e}}{\partial l}=a-b l-w-\lambda \gamma(m-w)^{2} l=0 \\
& \frac{\partial \pi^{e}}{\partial w}=-l+\lambda \gamma(m-w) l^{2}=0
\end{aligned}
$$

Solving these gives the following expressions for the optimum values of employment and wage:

$$
\begin{aligned}
& l^{e}=(a-m) / b \\
& w^{e}=m-\frac{b}{\lambda \gamma(a-m)}
\end{aligned}
$$

Note that (14) is constrained by the fact that we need $w^{e}>w^{c}$ and the parameter configuration has to satisfy this relationship. Thus employment is the same as with a fully enforced minimum wage as in Yaniv (2001), and is predicted to decline with the minimum wage. It is independent of the enforcement parameters $\lambda$ and $\gamma$. This is because the response to enforcement comes through choice of wage paid, to which we now turn.

The expression for $w^{e}$ shows that there will be a spread of wages below the minimum wage. Write the wage gap $g$ as

$$
g=m-w^{e}=\frac{b}{\lambda \gamma(a-m)}
$$

Prior to the introduction of the minimum wage, every worker is paid the competitive wage $w^{c}$ and employment is $l^{c}$. When the minimum wage $m$ is introduced it has two effects. First, it reduces employment from $l^{c}$ to $l^{e}$. Second, it increases wages from $w^{c}$ to $w^{e}$; the increase depending on the productivity parameters and on the enforcement parameters. Higher productivity firms (higher $a$ and lower $b$ ) will pay higher wages and will have a smaller gap relative to the minimum wage. A higher minimum wage will increase the wage gap for every productivity level, but greater intensity of enforcement, as measured by higher values of $\lambda$ or $\gamma$, will lower the wage gap.

Particular attention is paid in this paper to the proportional shortfall of the actual wage paid relative to the minimum wage. Denote this as

$$
v=\frac{m-w^{e}}{m}=\frac{b}{\lambda \gamma m(a-m)}
$$

It is easy to see that this proportional gap also falls with higher productivity and greater intensity of enforcement. However,

$$
\frac{\partial v}{\partial m}=\frac{b(2 m-a)}{\lambda \gamma(a-m)}
$$


Thus the proportional gap rises or falls with the minimum wage according as $m$ is greater or lesser than one half of $a$. Further,

$$
\frac{\partial^{2} v}{\partial m \partial v}=\frac{b(a-3 m)}{\lambda \gamma m^{2}(a-m)^{4}}
$$

whose sign depends on whether $m$ is greater or lesser than one third of $a$. Putting together (17) and (18) we can show that if $m$ is less than one third of $a$, then an increase in the minimum wage will reduce the proportionate gap by more, the larger was the gap to start with. However, for other parameter values the proportionate gap, although it will always fall, may fall less, the higher is the gap. The general point emerging from the discussion surrounding equations (17) and (18) is that even in this simplified model the behaviour of the proportional gap is complicated and ambiguous, and thus an empirical matter for further investigation.

Before concluding this theory section we note that although we have interpreted the costs of non-compliance for firms in terms of official enforcement and fines, other interpretations are also possible. For example, there might be peer pressures and social sanctions in terms of reputational effects for non-compliers. The magnitudes of these would naturally depend on the extent of non-compliance. Thus the costs of noncompliance specified in (10) as proportional to $(m-w)^{2} l^{2}$ can be interpreted directly as social opprobrium, being in proportion to the square of the shortfall of the wage bill from the minimum wage level. We will not be able to distinguish empirically between these different forces. But they all predict partial compliance to different degrees.

Thus we have rationalized the phenomenon of partial adjustment to a minimum wage when there is imperfect enforcement. However, even in this quite simple setting we get a rich set of predictions. There is partial adjustment but its extent is an empirical question. The next section begins our empirical analysis of partial compliance upon the introduction of the minimum wage in South African agriculture.

\section{Data and empirical strategy}

Legally binding national minimum wages set by the State have a relatively short history in South Africa. While there is currently no single national minimum wage, wage setting does apply to workers in specific sectors and occupations. ${ }^{2}$ The first such minimum wage policy was introduced in 1999 in the Contract Cleaning industry. This was followed by legislation for Private Security workers (2001), Domestic workers (2002) and workers in Wholesale and Retail (2003). Minimum wages in this case form part of a Sectoral Determination, which in addition to wages provides legislation on working hours, employment contracts, and over time. Officially the Minister of Labour is responsible for introducing and updating these wage schedules but the Minister's decisions rely on recommendations from a tripartite committee known as the Employment Conditions Commission (ECC). State institutions have also been introduced to enforce these new wage laws.

The minimum wage law in the Agricultural sector was promulgated in December 2002 and came into effect on the $1^{\text {st }}$ of March 2003, with separate wage levels for rural and urban areas. Wages were initially set at 800 Rands per month in urban areas (Area A) and 650 Rands per month in rural areas (Area B), and adjusted upward annually. ${ }^{3}$ Figure 1 shows the annual adjustments over a four year period 


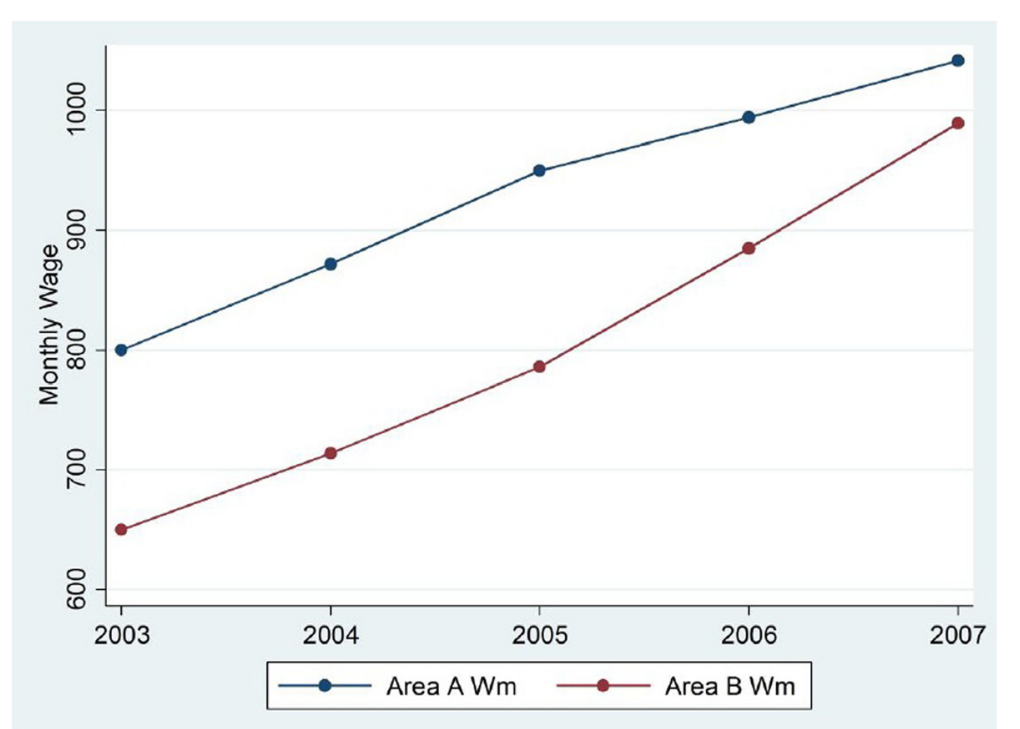

Fig. 1 Legislated minimum wage (in Rands/month), Area A and B, 2003-2007. Source: Department of Labour, Agriculture Sectoral Determinations (2003-2007)

from 2003-2007 - which is the focus of this section. We have analysed the impact of this minimum wage on employment in Bhorat et al. (2014). We find significant reductions in employment in the short run. We also find a significant rise in average wages. But what exactly happened to wages below the minimum? Was there full compliance, or partial compliance? And if compliance was partial, what were the nature of the adjustments that took place-were the lowest wages raised proportionately more, or less? Answering these questions is not straightforward because of the econometric issues involved in constructing appropriate counterfactuals but we attempt to explore them here.

Labor regulations in South Africa are accompanied by inspections and penalties for violations. These inspections are carried out by labour inspectors employed by the Inspection and Enforcement Services (IES) unit within the Department of Labour (DoL). The penalties for non-compliance are shown in Table 1. The upper section of the table refers to violations not concerned with underpayment of wages which attract specific monetary fines. The lower section refers to violations that do involve underpayment of wages and it is clear that while repeat offences and greater levels of underpayment attract larger penalties, in general the value of the fines are low. Also, given the resources allocated to the inspectorate, and the relatively small number of inspectors, the inspection rate is not high. For example, in the Western Cape Province (the only province for which we have detailed inspection data) the simple probability of a farmer being visited by a labor inspector in 2007 was 11 percent. The inspectorate also tries to ensure compliance through a combination of individual farm inspections, advertising, advocacy sessions with workers, and training programmes (Western Cape Government, 2010). There is thus an explicit attempt to publicise the law and create social pressure for compliance, alongside a more conventional inspection and enforcement structure. This social pressure can come from a number of sources, including peer effects. The influence of the latter effects though, is difficult to test with the data available to us, 
Table 1 Maximum permissible fines for violation (Schedule 2 of the BCEA, 1997)

\begin{tabular}{|c|c|}
\hline \multicolumn{2}{|l|}{ Maximum permissible fine not involving underpayment } \\
\hline No previous violation & R100 per employee \\
\hline $\begin{array}{l}\text { No previous violation in respect of the same provision of } \\
\text { the Act }\end{array}$ & R200 per employee \\
\hline $\begin{array}{l}\text { A previous violation the same year or two violations in } \\
\text { respect to the same provision during the past } 3 \text { years }\end{array}$ & R300 per employee \\
\hline 3 previous violations of the same provision within 3 years & R400 per employee \\
\hline 4 previous violations of the same provision within 3 years & R500 per employee \\
\hline \multicolumn{2}{|l|}{ Maximum permissible fine involving underpayment } \\
\hline No previous violation & $\begin{array}{l}25 \% \text { of the underpayment, including any interest } \\
\text { owing on the amount at the time of the order }\end{array}$ \\
\hline $\begin{array}{l}\text { A previous violation of the same provision during the } \\
\text { past } 3 \text { years }\end{array}$ & $\begin{array}{l}50 \% \text { of the amount due including applicable } \\
\text { interest }\end{array}$ \\
\hline $\begin{array}{l}\text { A previous violation of the same provision within a year, } \\
\text { or } 2 \text { previous violations, or } 2 \text { previous violations of the } \\
\text { same provision }\end{array}$ & $\begin{array}{l}75 \% \text { of the amount due, including applicable } \\
\text { interest }\end{array}$ \\
\hline $\begin{array}{l}3 \text { previous violations of the same provision during the } \\
\text { past three years }\end{array}$ & $\begin{array}{l}100 \% \text { of the amount due including applicable } \\
\text { interest }\end{array}$ \\
\hline $\begin{array}{l}3 \text { previous violations of the same provision during the } \\
\text { past three years }\end{array}$ & $\begin{array}{l}200 \% \text { of the amount due including applicable } \\
\text { interest }\end{array}$ \\
\hline
\end{tabular}

Fines not involving underpayment have been amended (Department of Labour 2014) but the figures above are those that relate to the period in question

and at this stage it is not possible to separate out official from non-official determinants of compliance. We restrict our focus to the nature of compliance.

The primary data for this paper are drawn from 14 waves of the South African Labour Force Survey (LFS), from February 2001 to September 2007, covering the period before and after the introduction of the minimum wage. ${ }^{4}$ The LFS is a biannual, rotating panel survey conducted in February/March and September each year. Our chosen sample includes five waves before the minimum wage legislation became effective (March 2003), and nine afterwards. Given that the law became effective at around the same time as the first 2003 survey we exclude the March 2003 wave from our econometric analysis. The remaining 13 waves are pooled and treated as repeated cross sections over time. The LFS covers approximately 30,000 households in each wave and this includes between 2,000 and 3,300 farmworkers per wave, over the period.

September 2003 is treated as the first wave where the direct impacts of the law should begin to be evident. As noted earlier two separate wage levels were prescribed for full-time farmworkers, according to geographic location: a higher minimum wage (Rands 800) for those working within urbanised municipal areas classified as Area A, and a lower wage (Rands 650) for predominantly rural areas classified as Area B. ${ }^{5}$ In order to evaluate which minimum wage applied to each individual, it was necessary to assign individuals to geographic areas. ${ }^{6}$ This was done by matching geographic information available in the LFS to areas A and B listed in the Sectoral Minimum Wage schedules. The sample includes both rural and urban workers, and includes full-time and part-time workers - defined as individuals working for at least $27 \mathrm{~h}$ per week, or less than $27 \mathrm{~h}$ a week, respectively. We restrict the sample to include only those classified as employees. 
Monthly wages reported in brackets in the LFS are transformed into point estimates by random allocation to a uniform distribution within the bracket to maintain variation. ${ }^{7}$ This accounts for between five and ten percent of the sample in each wave, on average. All monthly wages are then combined and converted into hourly wages, which we use for analysis. Employed individuals reporting zero or missing wages are excluded.

The key focus of our analysis is the impact of the introduction of the minimum wage on sub-minimum wages. For each agricultural worker in each wave of the survey we define

$$
\begin{aligned}
& \left.v_{\alpha}(m, w)=[m-w) / m\right]^{\alpha} \text { if } w<m \\
& v_{\alpha}(m, w)=0 \text { if } w \geq m
\end{aligned}
$$

where $m$ is the official minimum wage in a given year, and $w$ captures wages for each individual worker. We refer to $v^{\alpha}$ as the "violation index" for a particular worker. When $\alpha=0$ this is simply a count variable which takes on the value of 1 if the worker is below the minimum wage and 0 if the worker is above. When $\alpha=1$, the violation index is a measure of the proportional gap between farmworker wages and the minimum wage. This is of course the gap variable in equation (16). When $\alpha=2, v^{\alpha}$ becomes the squared gap and gives more weight to wages that fall further below the minimum. Our empirical focus will be on the effects of the law on $v^{1}$ and $v^{2}$ across workers.

Given the violation index, or proportional gap of reach worker, a measure of the aggregate gap is simply the average of (19) over all workers. Denoting the aggregate gap of violation as $V_{\alpha}$, if $h(w)$ is the frequency density of $\mathrm{w}$ then

$$
\begin{aligned}
V_{\alpha} & =\int v^{\alpha}(m, w) h(w) d w \\
& \left.=\int_{0}^{m}[m-w) / m\right]^{\alpha} h(w) d w
\end{aligned}
$$

This index of aggregate minimum wage non-compliance, which is analogous to the FGT index of poverty (Foster et al. 1984), was introduced by Bhorat et al. (2012, 2013a). We will also present patterns and trends in the aggregate gap in the next section.

To estimate the effects of the law on compliance we use two specifications. We first employ a standard difference-in-differences model analogous to Card and Krueger (1994):

$$
Y_{i k t}=\beta_{0}+\beta_{1} \text { POST }_{t}+\beta_{2} \text { Farmworker }_{k}+\beta_{3} \text { POST }_{t} * \text { Farmworker }_{k}+X_{i j t}+\varepsilon_{i k t}
$$

where, $Y_{i k t}$ is the outcome of interest $\left(v_{1}, v_{2}\right)$ for individual $i$, in group $k$, in period $t$. $\mathrm{POST}_{t}$ is the time dummy which captures 'before-and-after' effects. Farmworker ${ }_{k}$ is the dummy for whether an individual is in the treatment or comparison group $(k=1,2)$, which equals 1 if the individual is a farmworker and 0 if they are in the comparison group. POST $T_{t}$ Farmworker $_{k}$ is the difference-in-differences term which measures the difference between the outcomes of the treatment group versus those of the comparison group, across the pre- and post-law periods. This tests whether the observed changes in violation were shared by similar workers to whom the law did not apply, and for workers in the comparison group we calculate $\mathrm{V}^{1}$ using the agricultural 
minimum wage. Specifically the difference-in-differences coefficient measures the difference between what happened to farmworkers in the post-law period versus what happened to comparison group. This will correctly identify the effects of the minimum wage if there were no idiosyncratic shocks, in addition to the law that only affected farmworkers in the post period. ${ }^{8} X_{i j t}$ comparisons for various worker characteristics such as Age, Education, Race, provincial agricultural GDP, and if the individual has a written contract, and we run the regression with and without comparisons.

In an attempt to provide a counterfactual for what would have happened to wages in the absence of the minimum wage law we identify a comparison group that has similar characteristics to farmworkers. This is one part of our difference-in-differences identification strategy, which compares changes in farmworker compliance outcomes to a comparison group of comparable workers. The comparison group is made up of employees in unskilled or 'elementary' occupations, based on the 4-digit SASCO occupation codes and ISIC industry codes, earning less than the Basic Condition of Employment Act's (BCEA) income cut-off of R9 631 per month, aged between 15-65, who have completed no more than 12 years of schooling. In addition, union members, and those in sectors affected by another minimum wage, are excluded. For clarity, this group includes occupations such as: street vendors, packers, manufacturing and transport laborers, and elementary machine operators. The agricultural minimum wage law does not apply to them. Changes in the comparison group's wages provide an indication of movements in the economy that coincided with the period when the agricultural minimum wage was introduced, but were not the result of that policy change.

Secondly we specify another difference-in-differences model which tests to see whether the violation gap increased more in districts where farmworker wages were lower in the pre-law period":

$$
Y_{i j t}=\theta_{0}+\theta P O S T_{t}+\theta_{2} W G_{j}+\theta_{3} P O S T_{t} * W G_{j}+X_{i j t}+v_{i j t}
$$

where, $Y_{i j t}$ is the outcome of interest $\left(v_{1}, v_{2}\right)$ for individual $i$, in district $j$, in period $t$. $\mathrm{POST}_{t}$ is the time dummy, and $X_{i j t}$ comparisons for various worker characteristics. The wage gap $\left(W G_{j}\right)$ is a constructed variable which identifies cross-sectional variation between District Councils in the pre-law period. The wage gap is represented by:

$$
W G_{j}=\log \left[\operatorname{minimum}\left(w_{j}^{*}\right)\right]-\log \left[\operatorname{median}\left(w_{j}^{\prime}\right)\right],
$$

where $w_{j}^{*}$ is the initial minimum wage in district $\mathbf{j}$ and $w_{j}^{\prime}$ is the median agricultural worker wage in district $j$, in the year before the law was introduced. $w_{j}^{\prime}$ is calculated using real wages in 2002. Areas with a larger gap in the pre-law period would be expected to experience greater increases in wages in the post-law period if the law was binding. ${ }^{10}$

In equation (21) $\beta_{1}$ indicates the changes in the post-law period for both groups, $\beta_{2}$ gives the average difference between farmworkers and the comparison group over the full period, and $\beta_{3}$ shows the change for farmworkers in the post-law period relative to the comparison group. In equation (22) the parameter $\theta_{2}$ represents the average difference in outcomes for workers in low wage gap versus high wage gap areas across the entire period. $\theta_{3}$ is the difference-in-differences parameter, and tells us how much more outcomes changed in the post-law period, in areas where the wage gap was largest. 
Lastly, $\theta_{1}$ is also of interest as it tells us how the variable of interest changed on average after the law for a particular district, conditional on the wage gap being zero in that district. As in all such natural experiments we must assume that in the absence of the law, agricultural wages would be on the same general trend across districts, as well as for both groups of workers.

\section{Results}

Tables 2 and 3 present the results for the aggregate index of violation in equation (20) above, for the sample of farmworkers, in Areas A and B respectively. The first key result here is that $V_{0}$, the proportion of farmworkers earning less than the minimum wage specified for workers in both areas, declines over the period 2001-2007. This decline is relatively slow in both areas -11 percent in area $\mathrm{A}$ and 18 percent in area $\mathrm{B}$ - but is greater for farmworkers in Area B, who comprise 70-80 percent of all farmworkers over the period. Taken together, however, the results show that the proportion of workers whose wages increase to a level at or above the minimum wage is relatively small. Put differently, the estimates indicate substantial non-compliance with the law, as 54 percent of farmworkers in area A and 67 percent of workers in area B here still earn below the legislated minimum. Importantly, this measure can tell us nothing about wage movements below the minimum wage, which is in fact where the most significant changes have taken place. $V_{1}$, measuring the proportional gap between an individual's wage and the minimum wage, averaged over all individuals, is far more instructive in this regard. Table 2 reveals a decrease in the depth of aggregate violation: $V_{1}$ declines by 18 percent over the whole period but in particular falls by 30 percent in the year directly after the introduction of the law. In Area B Table 3 shows much larger decreases in the depth of violation, where overall $V_{1}$ falls by 45 percent, with a 24 percent decrease between 2002 and September 2003.

Table 2 Aggregate index of violation, Area A

\begin{tabular}{|c|c|c|c|c|}
\hline Year & $v_{0}$ & $V_{1}$ & $v_{2}$ & $v_{1} / v_{0}$ \\
\hline \multirow[t]{2}{*}{2001} & 0.61 & 0.20 & 0.10 & 0.33 \\
\hline & $(0.026)$ & $(0.014)$ & $(0.008)$ & \\
\hline \multirow[t]{2}{*}{2002} & 0.66 & 0.22 & 0.10 & 0.34 \\
\hline & $(0.025)$ & $(0.021)$ & $(0.016)$ & \\
\hline \multirow[t]{2}{*}{2003} & 0.60 & 0.15 & 0.06 & 0.26 \\
\hline & $(0.023)$ & $(0.010)$ & $(0.006)$ & \\
\hline \multirow[t]{2}{*}{2004} & 0.64 & 0.17 & 0.07 & 0.27 \\
\hline & $(0.024)$ & $(0.010)$ & $(0.006)$ & \\
\hline \multirow[t]{2}{*}{2005} & 0.65 & 0.19 & 0.09 & 0.30 \\
\hline & $(0.028)$ & $(0.017)$ & $(0.009)$ & \\
\hline \multirow[t]{2}{*}{2006} & 0.63 & 0.18 & 0.08 & 0.29 \\
\hline & $(0.033)$ & $(0.017)$ & $(0.009)$ & \\
\hline \multirow[t]{2}{*}{2007} & 0.54 & 0.16 & 0.07 & 0.30 \\
\hline & $(0.034)$ & $(0.0174)$ & $(0.009)$ & \\
\hline
\end{tabular}

Standard errors in parenthesis. $V_{0}$ is a headcount index which shows the percentage of farmworkers earning below the applicable minimum, $V_{1}$ is the average distance of wages below the minimum, and $V_{2}$ is the square of this gap which places more weight on observations furthest below the minimum. $V_{1} V_{0}$ is a simple ratio but allows for an easy interpretation of $V_{1}$ and can be read as: workers in year ' $x$ ' on average earn $V^{1} / V^{0}$ below the minimum 
Table 3 Aggregate index of violation, Area B

\begin{tabular}{|c|c|c|c|c|}
\hline Year & $v_{0}$ & $v_{1}$ & $v_{2}$ & $v_{1} / v_{0}$ \\
\hline \multirow[t]{2}{*}{2001} & 0.82 & 0.39 & 0.22 & 0.48 \\
\hline & $(0.014)$ & $(0.010)$ & $(0.008)$ & \\
\hline \multirow[t]{2}{*}{2002} & 0.83 & 0.39 & 0.23 & 0.48 \\
\hline & $(0.012)$ & $(0.011)$ & $(0.009)$ & \\
\hline \multirow[t]{2}{*}{2003} & 0.75 & 0.30 & 0.16 & 0.40 \\
\hline & $(0.014)$ & $(0.011)$ & $(0.008)$ & \\
\hline \multirow[t]{2}{*}{2004} & 0.72 & 0.25 & 0.13 & 0.35 \\
\hline & $(0.014)$ & $(0.009)$ & $(0.006)$ & \\
\hline \multirow[t]{2}{*}{2005} & 0.65 & 0.23 & 0.12 & 0.36 \\
\hline & $(0.019)$ & $(0.010)$ & $(0.007)$ & \\
\hline \multirow[t]{2}{*}{2006} & 0.65 & 0.23 & 0.11 & 0.35 \\
\hline & $(0.020)$ & $(0.011)$ & $(0.008)$ & \\
\hline \multirow[t]{2}{*}{2007} & 0.67 & 0.22 & 0.10 & 0.32 \\
\hline & $(0.020)$ & $(0.010)$ & $(0.006)$ & \\
\hline
\end{tabular}

Standard errors in parenthesis. $V_{0}$ is a headcount index which shows the percentage of farmworkers earning below the applicable minimum, $V_{1}$ is the average distance of wages below the minimum, and $V_{2}$ is the square of this gap which places more weight on observations furthest below the minimum. $V_{1} N_{0}$ is a simple ratio but allows for an easy interpretation of $V_{1}$ and can be read as: workers in year ' $x^{\prime}$ on average earn $V^{1} / V^{0}$ below the minimum

The estimates for $V_{2}$, which weights observations further below the minimum wage more heavily, show even sharper declines. Over the entire period $V_{2}$ falls by 22 percent among workers in area A and by 54 percent among workers in area B. In the year directly after the law is introduced this measure declines by over 30 percent in both areas. This suggests that workers further below the minimum in the pre-law period (or simply those with the lowest wages) were the greatest gainers in the post-law period. From equation (20) the ratio $V_{1} / V_{0}$ is simply the percentage shortfall of wages for farmworkers earning below the minimum; or put differently, violated workers in this sample are earning on average a fraction $V_{1} / V_{0}$ below the minimum wage. The data show that in 2002, workers who earned wages that were below the imminent minimum wage report wages that were on average 34 percent and 48 percent below the legislated minimum in areas A and B, respectively. In 2003, after the introduction of the law, these percentages fell 26 percent and 39 percent, both quite substantial decreases. The ratio begins to rise again among workers in area $\mathrm{A}$ but for the majority of workers (area B) the overall decrease in $V_{1} / V_{0}$ is 32 percent.

To illustrate changes in the depth of violation over time and across the wage distribution more clearly, Figs. 2 and 3 plot kernel density functions of $v_{1}$ across individuals for both the treatment and comparison groups. Equivalent plots for $v_{2}$ are shown in Figs. 4 and 5. Both figures for farmworkers show that the depth of violation and squared depth of violation decrease significantly after 2002, suggesting that once the law came into effect the depth of violation decreased, even if many farmworkers still earned subminimum wages. Crucially, also the V2 density results, reinforce the fact that even when we place greater weight on workers further below the minimum wage, employers of these workers were just as likely to partially comply with the law.

The evidence presented here, through the empirical lens of the violation index, and consistent with our theoretical predictions, suggests that employers may respond at the 


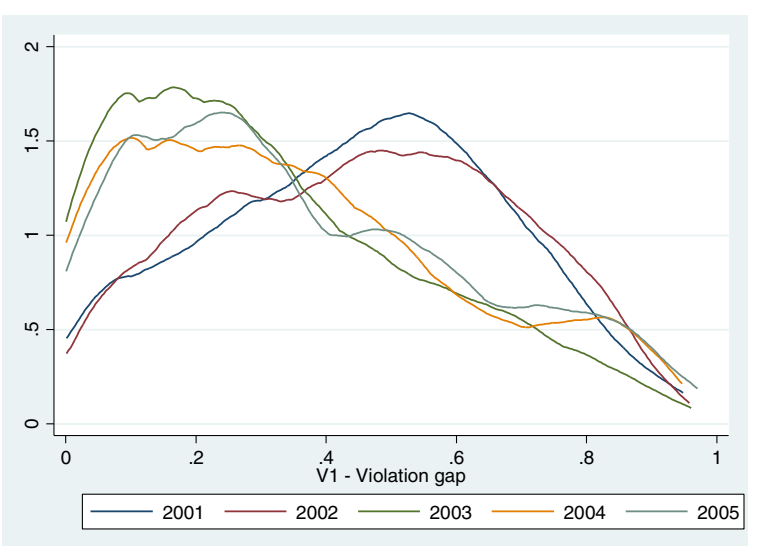

Fig. 2 Violation gap $\left(v_{1}\right)$ density function (2001-2005), farmworkers. Note: The figure is a kernel density plot of V1 for all farmworkers (Area A and B), calculated using the minimum wage for each year. Kolmogorov-Smirnov tests for equality of distributions are rejected at the $5 \%$ level for each pairwise comparison of waves in the before and after periods

margin to the institution of a minimum wage law. In particular, the results show that despite no 'spike' at the minimum wage level in agriculture, employers have responded by on average increasing the wages paid relative to the legislated minimum. In other words, there is partial compliance with the minimum wage law. In addition, for those workers further from the minimum wage, the post-law period yields larger marginal adjustment toward the minimum, as predicted for certain parameter values by equation (18).

The regression results from equation (21) are presented in Table 4 . The model is estimated separately for three dependent variables, which represent the simple measure of violation $\left(v_{0}\right)$, the depth of violation $\left(v_{1}\right)$, and the violation gap squared $\left(v_{2}\right)$. Each specification is run with and without comparisons. Columns 2 and 4 include comparisons for race, age, education, agricultural GDP, union status, and possession of a written employment contract.

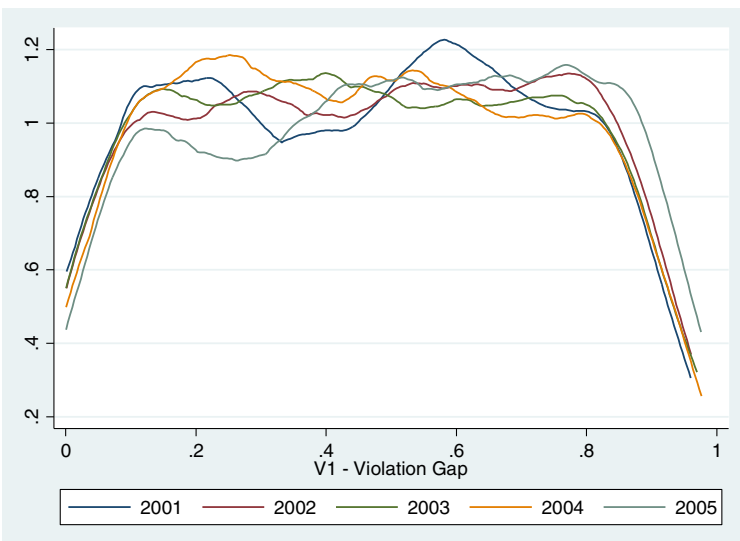

Fig. 3 Violation gap $\left(v_{1}\right)$ density function (2001-2005), comparison group. Note: The figure is a kernel density plot of $\mathrm{V} 2$ for all farmworkers (Area A and B), calculated using the minimum wage for each year. Kolmogorov-Smirnov tests for equality of distributions are not rejected at the $5 \%$ level for each pairwise comparison of waves in the before and after periods 


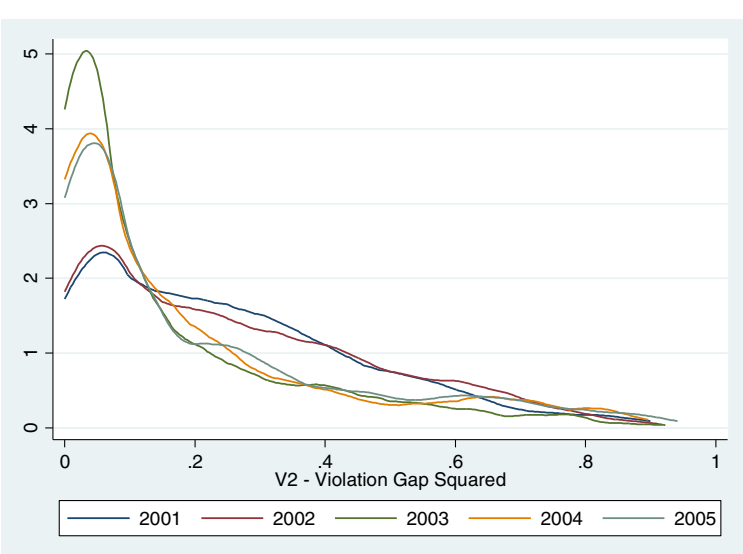

Fig. 4 Violation gap squared $\left(v_{2}\right)$ density function (2001-2005), farmworkers. Note: The figure is a kernel density plot of $\mathrm{V} 2$ for all farmworkers (Area A and B), calculated using the minimum wage for each year. Kolmogorov-Smirnov tests for equality of distributions are rejected at the $5 \%$ level for each pairwise comparison of waves in the before and after periods

The coefficient on the farmworker variable for $v_{0}$ shows that on average farmworkers earn lower wages than workers in the comparison group - the average number of farmworkers who earn below the agricultural minimum wage is higher by 40 percentage points in specification 2. Of primary interest is the difference-in-differences estimator (Farmworker"POST). Here the results suggest that relative to workers in the comparison group, the level of violation falls by approximately 2.5 percent in the postlaw period when we control for individual characteristics. This provides some support for the descriptive statistics which suggest small declines in $v_{0}$ after the law was introduced.

The estimates on $v_{1}$ initially suggest that the depth of violation among farmworkers is low relative to the comparison group but this effect disappears when we add controls, suggesting that after taking account of age, education, race and so on, $v_{1}$ is larger for farmworkers over the period. Put differently, farmworkers earn wages that are

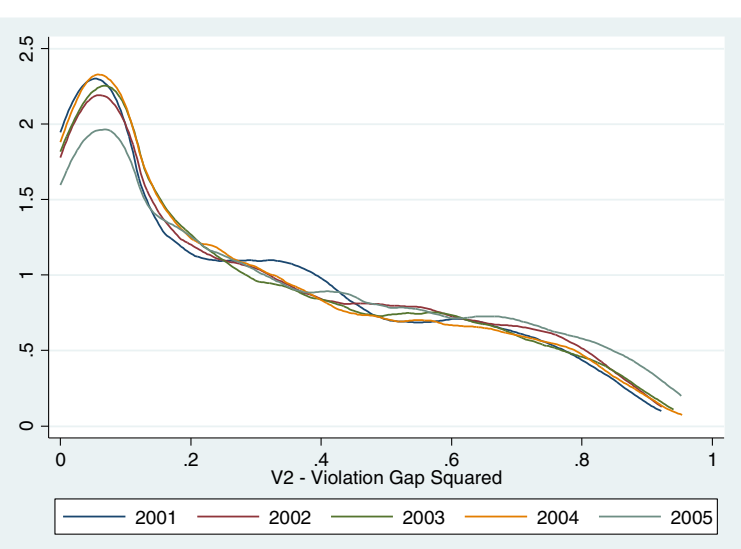

Fig. 5 Violation gap squared $\left(v_{2}\right)$ density function (2001-2005), comparison group. Note: The figure is a kernel density plot of $\mathrm{V} 2$ for all farmworkers (Area A and B), calculated using the minimum wage for each year 
Table 4 Partial compliance, depth of violation - treatment vs comparison group

\begin{tabular}{|c|c|c|c|c|c|c|}
\hline \multirow[t]{2}{*}{ Variables } & \multicolumn{2}{|l|}{$v_{0}$} & \multicolumn{2}{|l|}{$v_{1}$} & \multicolumn{2}{|l|}{$v_{2}$} \\
\hline & (1) & (2) & (3) & (4) & (5) & (6) \\
\hline \multirow[t]{2}{*}{ Farmworker } & $0.299^{* * *}$ & $0.399^{* * *}$ & $0.0116^{* * *}$ & $0.0730^{* * *}$ & -0.00344 & $0.0500^{* * *}$ \\
\hline & $(0.00575)$ & $(0.00677)$ & $(0.00413)$ & $(0.00506)$ & $(0.00396)$ & $(0.00434)$ \\
\hline \multirow[t]{2}{*}{ POST } & $-0.0246^{* * *}$ & $0.0123^{* *}$ & $-0.0102^{* * *}$ & -0.00333 & $-0.00833^{* *}$ & -0.00355 \\
\hline & $(0.00438)$ & $(0.00497)$ & $(0.00365)$ & $(0.00476)$ & $(0.00350)$ & $(0.00408)$ \\
\hline \multirow[t]{2}{*}{ Farmworker*POST } & -0.00545 & $-0.0247^{* * *}$ & $-0.119^{* * *}$ & $-0.0883^{* * *}$ & $-0.0975^{* * *}$ & $-0.0636^{* * *}$ \\
\hline & $(0.00741)$ & $(0.00784)$ & $(0.00530)$ & $(0.00592)$ & $(0.00507)$ & $(0.00508)$ \\
\hline Comparisons & NO & YES & NO & YES & NO & YES \\
\hline \multirow[t]{2}{*}{ Constant } & $0.450^{* * *}$ & $0.732^{* * *}$ & $0.481^{* * *}$ & $0.552^{* * *}$ & $0.304^{* * *}$ & $0.353^{* * *}$ \\
\hline & $(0.00371)$ & $(0.0166)$ & $(0.00307)$ & $(0.0273)$ & $(0.00294)$ & $(0.0234)$ \\
\hline Observations & 84,924 & 58,186 & 42,760 & 26,623 & 42,760 & 26,623 \\
\hline R-squared & 0.077 & 0.302 & 0.034 & 0.129 & 0.030 & 0.106 \\
\hline
\end{tabular}

*** $p<0.01,{ }^{* *} p<0.05, * p<0.1$. Standard errors are in parentheses. $V_{0}$ is a headcount index which shows the percentage of farmworkers earning below the applicable minimum, $V_{1}$ measures the gap between an individual's wage the minimum wage, while $V_{2}$ is the squared gap which gives more weight to wages at the bottom of the distribution. The minimum wage used to construct both measures is the same for both the treatment and comparison groups

further below the agricultural minimum wage than their counterparts in the comparison group, although the difference is not large. The $\mathrm{POST}_{t}$ coefficient suggests that when the two groups are taken together no large changes in levels of violation are observed, but again this difference is small. The difference-in-differences estimator, however, is both negative and significant for $v_{1}$ and $v_{2}$, and remains stable when comparisons are added. This reveals that relative to the comparison group, farmworkers experienced a notable decrease in the depth of violation in the post-law period; when we control for individual characteristics the average depth of violation fall by almost nine percent, while the squared gap falls by six percent. The results for $v_{2}$ provide some evidence that workers with wages further away from the minimum saw wages rise as a result of the law, although they continued to earn sub-minimum wages. These results underscore the trends evident in kernel density distributions showing a move in wages toward, but not up to, the minimum wage as a result of the law. The notion that this result is consistent even when placing a higher weight on workers further from the minimum wage - suggests that partial compliance with the law may be invariant to how low pre-law wages are.

Table 5 presents the regression results of equation (22), estimated only for the sample of farmworkers. Here we test for whether compliance with the agricultural minimum wage falls by more in districts where the average wage gap was larger in the pre-law period. We do this for $v_{1}$ and $v_{2}$. The coefficient on the wage gap is positive and significant across all specifications, suggesting that in areas where the district wage gap is larger, individual levels of violation are higher for the entire period; this is robust to the addition of comparisons. As in the previous regressions, the POST coefficient suggests that levels of violation for farmworkers fell in the post-law period. Of primary interest, the difference-in-differences estimator shows that levels of violation fell by more in areas where the initial district wage gap was larger. This is robust to addition of individual-level controls, for both $v_{1}$ and $v_{2}$, and suggests changes of 6.8-7.8 percent for $v_{1}$ and changes of 7.1-7.9 percent for $v_{2}$. In other words, we observe greater levels of 
Table 5 Partial compliance, depth of violation - wage gap

\begin{tabular}{lllll}
\hline Variables & $V^{1}$ & & $V^{2}$ & \\
\hline Wage Gap & $0.163^{* * *}$ & $0.104^{* * *}$ & $0.159^{* * *}$ & $0.106^{* * *}$ \\
POST & $(0.00435)$ & $(0.00701)$ & $(0.00403)$ & $(0.00607)$ \\
& $-0.0517^{* * *}$ & $-0.0381^{* * *}$ & $-0.0269^{* * *}$ & $-0.0130^{* *}$ \\
Wage Gap*POST & $(0.00682)$ & $(0.00706)$ & $(0.00632)$ & $(0.00611)$ \\
& $-0.0680^{* * *}$ & $-0.0780^{* * *}$ & $-0.0710^{* * *}$ & $-0.0789^{* * *}$ \\
Comparisons & $(0.00699)$ & $(0.00865)$ & $(0.00647)$ & $(0.00749)$ \\
Constant & NO & YES & NO & YES \\
Observations & $0.339^{* * *}$ & $0.400^{* * *}$ & $0.150^{* * *}$ & $0.173^{* * *}$ \\
R-squared & $(0.00471)$ & $(0.0407)$ & $(0.00437)$ & $(0.0352)$ \\
\hline
\end{tabular}

*** $p<0.01,{ }^{* *} p<0.05,{ }^{*} p<0.1$. Standard errors are in parentheses. $V_{1}$ measures the gap between an individual's wage the minimum wage, while $V_{2}$ is the squared gap which gives more weight to wages at the bottom of the distribution. The minimum wage used to construct both measures is the same for both the treatment and comparison groups

partial compliance in areas where prior to the law, workers were receiving lower wages. The results also reinforce that workers with larger wages gaps moved closer to the minimum wage, on average.

Using these regression techniques to examine changes in the depth of violation serves to illustrate how sub-minimum wages in the agricultural sector have responded to the introduction of the minimum wage law and supports the descriptive picture presented above. Evidence suggests that while levels of violation remained high, many employers do not simply make a discrete decision - either to comply with, or violate, the law. Instead, it would appear that employers choose by how much to comply with the law, representing this crucial theoretical and empirical observation of partial compliance with the law. In addition to the k-density functions then, the regressions reveal a wide spread of sub-minimum wages, that increase partially but not all the way up to the minimum wage, in response to the law. It is this varied distribution of partial compliance levels - measured and modelled through $v_{1}$ and $v_{2}$ here - which is the important value-add of this paper in terms of understanding the typology of employer responses to the institution of minimum wage regulations.

\section{Conclusion}

When a minimum wage law is introduced, what happens to wages that were below the legal minimum wage? If there is perfect enforcement, we should not observe any workers earning below the minimum wage. With imperfect enforcement there will be wages below the minimum wage, but how does the sub-minimum wage distribution after the law compare to that distribution before the law was passed? This paper attempts to provide answers to these questions using the fact that for South Africa, wage distribution data is available for a period before and after the promulgation of a minimum wage law in agriculture.

The paper begins by developing a simple theoretical model in which the obvious benefits of non-compliance for an employer are to be set against the costs of noncompliance. We model these as composed of the probability of getting caught, and 
the fine imposed if caught. However, alternative interpretations of the costs of non-compliance are possible, including peer effects. We model the costs of noncompliance as a function of the total short fall of the wage bill compared to full compliance, allowing for the possibility that employers adjust partially towards the minimum wage. The model predicts that employment will fall as the result of a minimum wage, but that a spread of wages below the minimum wage should be observed in response to the law. Employer responses to a minimum wage law depend on the level at which the minimum wage is set, relative to the existing wage. Wages will rise towards the minimum wage, and under certain conditions, the lowest wages will rise proportionately more than those close to the stipulated minimum.

We then turn to an empirical application based on the agriculture sector in South Africa, focusing on wage effects. We utilise an index of minimum wage violation to estimate whether relative compliance levels, measured here by a closing of the average gap between actual and minimum wages, have changed as a result of the promulgation of the minima. We find that there is evidence of partial compliance, where employers adjust wages upwards as a result of the law, but not all the way to the minimum wage. This supports work by Dinkelman and Ranchhod (2012), Dinkelman et al. (2014) who observe partial response to the minimum wage law in the Domestic Worker sector in South Africa. However, unlike Dinkelman and Ranchhod (2012), we find that when the minimum wage is set at a higher level relative to existing mean wages in a district, there is evidence of greater partial compliance, which is predicted by the theoretical model for some parameter values.

The data indicate that while the fraction of workers paid below the minimum wage decreases over time in response to the law, the levels of non-compliance remain high. More than half of farmworkers report earning wages below the prescribed minimum in 2007. The relatively low levels of compliance imply that official enforcement efforts, and non-official pressures, are not sufficient. It may also be plausible that the government initially accepted low levels of compliance after the introduction of the law and thus did not commit substantial resources to enforcement. ${ }^{11}$ Nonetheless, given that the state continually engages in numerous enforcement activities to try and ensure compliance, it is plausible that these formal enforcement efforts have had some observable, if partial, influence on compliance, resulting in some low-level partial compliance equilibrium.

Based on these results there is scope for more research. Our results suggest strongly that we need to think of responses to the minimum wage in a continuous rather than a discrete manner. In particular, our estimates of the depth and severity of violation suggest that whilst employers do respond positively to the introduction of a minimum wage, this is often not in complete adherence with the law. Moreover, it appears that areas where wages were lower in the pre-law period, and for workers with wages further below the minimum wage, we observe greater levels of partial compliance. The argument for stricter enforcement is further strengthened by the result of our model, and the more general analysis of Yaniv (2001), that the employment effect depends only on the minimum wage and not on intensity of enforcement if employers are adjusting optimally, albeit partially, to the law. This notion of partial compliance with responses at the margin to the law deserves further and closer attention in the minimum wage literature. 


\section{Endnotes}

${ }^{1}$ There are in principle three choice variables the employer has: (i) the number of workers paid the minimum wage; (ii) the number of workers paid the sub-minimum wage; (iii) the level of the sub-minimum wage. The previous literature fixed (iii) at the competitive wage, and fixed (i) at zero, leaving only the choice of (ii). Yaniv (2001) also fixed (iii) at the competitive wage but allowed choice of (i) and (ii). Since our focus in this paper is on understanding the behaviour of the wage distribution below the minimum wage, our theory focuses on choice on (iii) but shuts down the distinction between (i) and (ii) - all workers are paid the subminimum wage. Our specific functional forms give closed form solutions which help in developing comparative statics and thus in structuring the empirical analysis which is the core of the paper. In fact, given the linear quadratic structure of our model, and the way the probability of detection and fines if detected are specified, it can be shown that when choice of (i), (ii) and (iii) is allowed the choice of (ii) and (iii) lies on a relationship and any choice along this relationship will be optimal. The particular point along the relationship shown in the paper is the subminimum wage such that all workers are paid that wage (both optimally chosen). This extension of the model is available from the authors but would needlessly complicate the exposition here.

${ }^{2}$ This system runs in tandem with collective bargaining at the industry level (see Theron et al. 2007).

${ }^{3}$ An hourly minimum wage is also set, which is equivalent to the monthly rate.

${ }^{4}$ The next three paragraphs are based on Bhorat et al. (2014), which uses the same dataset.

${ }^{5}$ This demarcation was based on the average household income recorded for the municipal area concerned in the 1996 census, where:

A. Average income greater than Rands 24, 000 per annum

B. Average income between Rands 12, 000 and Rands 24, 000 per annum.

Areas with average income below Rands 12, 000 are included in Area B. Since 2009, the demarcation between Area A and Area B was removed, and Area A schedules now apply nationally. We use geographical information on Magisterial Districts and District Councils in the LFS to demarcate areas A and B.

${ }^{6} \mathrm{We}$ are however, unable to differentiate between place of residence and place of work for individuals, though we would argue that this is not as problematic for the agricultural sector as it might be for some other sectors. Although there are no reliable national figures we assume that the majority of full-time farmworkers still live on the farm and there is some evidence to suggest this is so: During the South African Human Rights Commission's 2007 hearings on farmworkers and farm dwellers, Agriculture South Africa stated that, in addition to workers, approximately 4 million people lived on farms but were not employed there. This suggests that the number of farmworkers living on farms is still significant if we assume the average household size for South Africa applies to these households. Moreover, the Department of Land Affairs held that the majority of full time farmworkers still live on farms (Human Rights Watch, 2011).

${ }^{7} \mathrm{~A}$ new seed is set in STATA for each bracket calculation. 
${ }^{8}$ In order to comparison for changes specific to the agricultural sector that may bias our results, we tested using agricultural GDP as well as Net Agricultural Income as independent variables in our regression. Neither variable had any significant impact on our results.

${ }^{9}$ This approach follows Lee (1999), and Dinkelman and Ranchhod (2012).

${ }^{10}$ In order for us to identify the effect of the minimum wage law we must assume that in the absence of the law change, low wage-gap districts would be on the same trend in outcomes as high wage gap districts (as in Dinkelman \& Ranchhod, 2012). We must also assume that changes in demand for labor were uniform. A review of the recent agricultural economics literature for South Africa gives us no reason to believe that there were price or non-price changes which may have caused labor demand to differ by geography in the post-law period.

${ }^{11}$ Interviews in the Western Cape, and a 2012 survey of Labour Inspectors conducted by the Development Policy Research Unit (DPRU) at the University of Cape Town, reveal a severe lack of resources in the IES. This is supported by an ILO (2010) report on the inspectorate in South Africa and administrative data from the Department of Labour. In particular, there are too few inspectors, inspectors are poorly trained and under-remunerated for their quasi-legal roles, and Labour Centres are underequipped, specifically lacking in vehicles and computers according to inspectors and IES officials.

Competing interests

The IZA Journal of Labor and Development is committed to the IZA Guiding Principles of Research Integrity. The authors declare that they have observed these principles.

\section{Acknowledgements}

This paper was first presented at a global conference entitled Reforming Minimum Wage and Labor Regulation Policy in Developing and Transition Economies held at Beijing Normal University, October 18-19, 2014, Beijing, China. The authors gratefully acknowledge the detailed and constructive comments on this manuscript, offered by two anonymous referees. Responsible editor: David Lam

\section{Author details}

${ }^{1}$ Development Policy Research Unit, University of Cape Town, Cape Town 7700, South Africa. ${ }^{2}$ Cornell University, Ithaca, NY 14853-7801, USA.

Published online: 16 November 2015

\section{References}

Ashenfelter O, Smith R (1979) Compliance with the minimum wage law. J Polit Econ 1979(2):333-350

Basu A, Chau N, Kanbur R (2010) Turning a blind eye: costly enforcement, credible commitment, and minimum wage laws. Econ J 120(543):244-269

Bhorat H, Kanbur R, Mayet N (2012) Minimum wage violation in south africa. Int Labour Rev 151.2012(3):277-287

Bhorat H, Kanbur R, Mayet N (2013a) A note on measuring the depth of minimum wage violation. Labour 27(2):192-197

Bhorat H, Kanbur R, Mayet N (2013b) Estimating the causal effect of enforcement on minimum wage compliance: the case of South Africa. Rev Dev Econ 16(4):608-623

Bhorat H, Kanbur R, Stanwix B (2014) Estimating the impact of minimum wages on employment, wages and non-wage benefits: the case of agriculture in South Africa. Am J Agric Econ 96(5):1402-1419

Card D, Krueger AB (1994) Minimum wages and employment: a case study of the fast-food industry in New Jersey and Pennsylvania. Am Econ Rev 84:772-793

Chang YM, Ehrlich I (1985) On the economics of compliance with the minimum wage law. J Polit Econ 93(1):84-91

Department of Labour (2014) Basic Condition of Employment Amendment Act, 2013: Commencement, SA Government Gazette Vol. 590, No. 37955, Pretoria: 2014

Dinkelman T, Ranchhod V (2012) Evidence on the impact of minimum wage laws in an informal sector: domestic workers in South Africa. J Dev Econ 99(1):27-45

Dinkelman T, Ranchhod V, Hofmeyr C (2014) Enforcement and compliance: The case of minimum wages and mandatory contracts for domestic workers in South Africa., Available at: www.econ3x3.org. Accessed 29 July 2015

Foster J, Greer J, Thorbecke E (1984) A class of decomposable poverty measures. Econometrica 52(3):761-766

Grenier G (1982) On compliance with the minimum wage law. J Polit Econ 90(1):184-187

Human Rights Watch (2011). Ripe with abuse, human rights conditions in South Africa's Fruit and Wine Industry. Available at: https://www.hrw.org/report/2011/08/23/ripe-abuse/human-rights-conditions-south-africas-fruit-andwine-industries. Accessed 29 July 2015

ILO (2010) "Global Wage Report 2010/11, Wage Policies in Times of Crisis", ISBN 978-92-2-123622-1. 
Lee D (1999) "Wage Inequality in the United States During the 1980s: Rising Dispersion or Falling Minimum Wage?" Quarterly Journal of Economics, 114(3):977-1023

Neumark D, Schweitzer M, Wascher W (2000) The effects of minimum wages throughout the wage distribution, NBER Working Paper 7519. National Bureau of Economic Research, Cambridge

Stigler G (1946) The economics of minimum wage legislation. Am Econ Rev 36(3):358-365

Theron J, Godfrey S, Visser M (2007) Globalization, the impact of trade liberalization, and labour law: The case of South Africa. International Institute for Labour Studies, Geneva

Western Cape Government (2010). Provincial Inspection Plan, Inspection and Enforcement Services, Department of Labour. Internal Document, Cape Town

Yaniv G (2001) Minimum wage noncompliance and the employment decision. J Labor Econ 19:596-603

Submit your manuscript to a SpringerOpen ${ }^{\circ}$ journal and benefit from:

- Convenient online submission

Rigorous peer review

- Immediate publication on acceptance

- Open access: articles freely available online

- High visibility within the field

Retaining the copyright to your article

Submit your next manuscript at $\gg$ springeropen.com 